\title{
Balancing the Rights of European Citizenship with Duties Towards National Citizens: An Inter-National Perspective
}

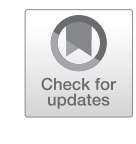

\author{
Richard Bellamy
}

\begin{abstract}
Discussions of European citizenship have tended to mobilise around two somewhat divergent views. The first view, well represented by Maurizio Ferrera's argument for his ingenious proposals, treats this status instrumentally: as a mechanism for promoting both greater allegiance to the EU from those individuals subject to its authority and greater solidarity amongst them. As with Ferrera's argument, such views tend to conceive European citizenship in analogous terms to citizenship within the member states, with the goal being to wean individuals away from the national to the supranational, at least to some degree (Habermas's 1992 essay remains the classic statement of this approach). ${ }^{1}$ By contrast, the second view, of which Christian Joppke's contribution offers a fine example, treats European citizenship as transnational. So conceived, it involves not only denationalising citizenship but also transforming the very nature of citizenship itself. ${ }^{2}$ A citizen becomes no more than an individual bearer of liberal rights, with no special duties to any particular political community but only the moral obligations to uphold the liberal rights of all other individuals (actually Joppke is silent on this issue, but I assume de-dutification can only be taken so far).
\end{abstract}

Although Ferrera's account moves in the direction of a supranational view, his policy proposals occupy a mid-point, providing a transitionary phase that seeks to reconcile the national to the transnational. By contrast to Joppke, I believe such a reconciliation is not only a pragmatically necessary endeavour but also normatively justifiable. However, I shall argue that the grounds for doing so indicate difficulties with the conventional supra- and

1 Habermas, J (1992), 'Citizenship and National Identity: Some Reflections on the Future of Europe', Praxis International, 12 (1): 1-19.

2 For full accounts of this thesis, see: Kochenov, D. (2014), 'EU Citizenship without Duties', European Law Journal 20 (4): 482-498; Kostakopolou, D. (2004), 'European Union Citizenship: Writing the Future', European Law Journal 13 (5): 623-646. 
trans-national views of European citizenship, and point to an alternative view that I shall call inter-national.

As Andrea Sangiovanni has observed in his contribution, Ferrera's declared grounding for his proposals beg the question of why the vast majority of citizens of the different member states, who do not themselves take advantage of freedom of movement, should view further European integration and the creation of social solidarity at the European level as desirable in the first place. Although Ferrera does not articulate his reasoning explicitly, the implicit rationale would appear to be the two standard functional and moral arguments that are habitually offered for an ever closer Union. The functionalist case contends that in an interconnected world, the only way to take advantage of the economic benefits globalisation brings while managing its costs is through scaling up beyond the nation state. The moral case involves a form of cosmopolitanism, whereby the argument holds that if we are to treat all individuals as of equal moral worth we must likewise remove those political boundaries that entail treating them unequally. Both these arguments certainly need to be taken seriously. Whether they can only be adequately or appropriately addressed by a scaling up of political authority to the regional level or beyond is another matter. ${ }^{3}$

Given these arguments, the obvious question to ask is why we should take national citizenship seriously at all? As Joppke contends, surely the moral argument in particular suggests we should avoid either pandering to nationalism in the short term or replicating its exclusionary characteristics at the supranational level in the long term? One reason arises from the fact that, for all their faults, democratic nation states, such as those that are members of the EU, provide the most effective political systems so far devised for rendering governments accountable to the governed in ways that encourage these governments to pursue policies aimed at treating the governed with equal concern and respect, and thereby securing their rights. Pace the transnational de-dutifyers, individual rights claims are likely to go unheeded without some political and legal authority capable of upholding them consistently and coherently over time. Meanwhile, that authority will only be likely to uphold these rights in an impartial and fair way if suitably constrained to do so, with the most effective constraint being to subject rulers to a system of equal influence and control by the ruled. As a result of such a set

3 For a discussion of these two views, see: Bellamy, R. (2015), 'Between Cosmopolis and Community: Justice and Legitimacy in A European Union of Peoples', in S. Tierney (ed.), Nationalism and Globalisation: New Settings, New Challenges, 207-232. London: Hart. 
up, citizenship becomes the 'right to have rights' ${ }^{4}$ Indeed, it could be argued that it is only within such a context that rights can be either effectively or legitimately claimed. ${ }^{5}$ For it is only through participating, on the one hand, in a scheme of social and economic cooperation capable of supporting expenditure on a suitable public infrastructure needed to secure rights; and, on the other hand, within a scheme of political cooperation through which individual rights can be claimed, justified and agreed to on equal terms to others, that a system of rights that is fair and sustainable can emerge. The duties that arise from involvement in these two schemes may have gained a romantic, nationalist colouring, yet as Andrea Sangiovanni notes they are for the most part prosaic - paying taxes, treating others with civility - not least by accepting the rules of the political game, and acknowledging the obligation to treat others with equal concern and respect.

The transnational view tends to overlook the role democratic states have had and continue to have in generating rights not only for their citizens but also for those citizens of other countries who may temporarily move to visit or work there. They treat them as self-evident moral properties of individuals that apparently can be met spontaneously. ${ }^{6}$ Many proponents of the transnational view among legal academics have also been overly sanguine about the judicialisation of the EUs transnational citizenship provisions, which has largely occurred as an extension of the lex mercatoria of the single market. ${ }^{7}$ As Susanne Schmidt remarks in her contribution, the deployment of litigation by market actors gains a false legitimacy from exploiting the terminology of citizenship rights. For it allows those actors with an economic interest in further market integration - the majority of which are enterprises rather than individuals - a privileged venue that is biased against, and often inaccessible by, the immobile majority, undermining the relative political equality offered by democratic citizenship. ${ }^{8}$ Nevertheless, transnational critics are right to note that many of these same states have been, and

4 See: Bellamy, R. (2001), "The "Right to have Rights": Citizenship Practice and the Political Constitution of the EU', in R. Bellamy and A. Warleigh (eds.)

Citizenship and Governance in the European Union, 41-70. London;

New York: Continuum

5 Bellamy, R. (2012a), 'Rights as Democracy', Critical Review of International Social and Political Philosophy, 15 (4): 449-471.

6 For a detailed critique see: Bellamy, R. (2015), 'A Duty-Free Europe? What's Wrong with Kochenov's Account of EU Citizenship Rights', European Law Journal 21 (4): 558-565.

7 Bellamy, R. (2015b), see above.

8 Isiksel, T. (2016), Europe's Functional Constitution: A Theory of Constitutionalism Beyond the State. Oxford: Oxford University Press, 142-143. 
still can be, great sources of injustice for those individuals and whole peoples they have dominated either directly, through colonisation and war, or indirectly, through exploitative trade deals, and who they continue to exclude through various immigration policies.

In this regard, the supranational solution might seem superior because it can overcome the possibility of domination and exclusion simply by being more inclusive of who is a citizen. Yet, as Ferrera acknowledges, establishing anything coming close to such a social and political system at the national level required a long period of political struggle facilitated by mass conscription in war, which gave ordinary people a degree of leverage over those whose wars they were obliged to fight - not least in prompting the establishment of social insurance and ultimately the granting of universal adult suffrage. Meanwhile, a degree of bonding sufficient to agree upon and abide by collectively binding decisions was facilitated not only by boundaries delineating among whom they were made and to whom they applied, as Ferrera reports, but also by a common history, culture and language. These latter features in particular may belong to the romantic attachments that Joppke deplores as reactionary throw-backs, but they served a functional purpose in facilitating the operation of democracy as a mechanism for the public realisation of the equal status of citizens. For to achieve that result, citizens must be able to air their disagreements and deliberate in ways all can see are fair and addressed to their common concerns, all of which assumes a public sphere and shared interests. As the events currently unfolding in Catalonia indicate, where these features are deemed to be lacking, then large numbers of people are likely to be willing to exercise their liberal rights to freedom of speech and association to militate for a political community that can embody them and can only be prevented from doing so through coercion.

Such factors make a rapid shift to supra-nationalism unlikely if not unfeasible a priori. Even if achievable, however, it may also be undesirable. There are a plurality of reasonable ways of combining and pursuing the goods that give value to human lives, and even among liberal democracies there can be found a variety of economic, social, legal and political systems. Within a large, socially and culturally diverse political unit, the risk of common policies being inefficient and inequitable increases, along with the prospect of majority tyranny over consistent minorities. Finally, just as in a domestic political system, checks and balances between different institutions can be important for ensuring that individuals and groups of individuals all get treated with equal concern and respect in the making and implementation of collective policies, so a collaborative system of mutually checking and balancing states can operate in a similar manner.

Against this background, an alternative characterisation of Ferrera's proposals holds that they comprise not transitional steps aimed at easing and 
promoting a gradual shift towards the development of a European supranational citizenship but as components of an inter-national European citizenship designed to supplement rather supplant national citizenship in response to the functional and moral arguments reported above. Such a status forms part of a more general international arrangement aimed at promoting equality of concern and respect between the citizenship regimes of its constituent member states, not least by facilitating the movement of citizens between these different regimes. Within an interconnected world, the national citizens of democratic states can be regarded as having obligations not to dominate the national citizens of other democratic states, not least by undercutting their capacity for self-government. They also have joint obligations to address problems that can only be tackled through collaboration and that involve harms and injustices that almost all moral systems regard as such. These include the prevention of the most egregious infringements of basic human rights, and the need to tackle global poverty and avoid a climatic catastrophe. A feature of such an arrangement is that it does not seek to subsume national citizenship regimes within a more encompassing supranational regime but rather to facilitate their effective and legitimate operation through cooperation and the mutual regulation of their interactions.

I have argued elsewhere that to a large, if imperfect, extent the EU conforms to this kind of arrangement, ${ }^{9}$ not least through its decision making involving the normative logic of a two-level game whereby governments reach consensual agreements as the representatives of their respective peoples, from whom these agreements must be capable of winning their acceptance over time. I call such an arrangement a form of 'republican intergovernmentalism'. Union citizenship likewise can be assimilated to this account as a form of inter-national citizenship. Inter-national citizenship has two main aims. On the one hand, it addresses both the functional and the cosmopolitan critiques of national citizenship regimes by allowing citizens to move freely between these regimes without discrimination on grounds of nationality so far as access to employment or short or long-term residence is concerned. On the other hand, though, it remains justified to maintain the viability and diversity of these citizenship regimes and the solidarity among national citizens that make them possible. After all, they remain the source of the rights that mobile citizens move to enjoy. That can involve rules limiting immediate access to certain social benefits in the case of individuals who have yet to find employment and contribute to them. It would also justify giving a vote only in local as opposed to national elections for those unwilling to become national citizens and to commit to the future sustainability of

9 Bellamy, R. (2013), 'An Ever Closer Union of Peoples: Republican Intergovernmentalism, Demoi-cracy and Representation in the EU', Journal of European Integration 35 (5): 499-516. 
the citizenship regime. Finally, it would entail the possibility - as suggested by Ferrera - for states that are a party to this arrangement to collectively agree on some indemnification for those national citizens who lose out. Note that in this conception of citizenship the source of rights is strictly speaking provided by the contracting states that agree to this arrangement and fulfil the obligations necessary to their realisation rather than any supra-national entity per se. Hence, it is logical that the entitlement to access this status stems from being a citizen of one of the contracting states. Moreover, the rights associated with an 'inter-national' conception are 'isopolitical' rather than 'sympolitical'. The policies that Ferrera proposes can all be offered on this account on 'isopolitical' grounds - as part of the mutual recognition and associated duties of the citizenship regimes of the member states.

As I remarked, this account fits the existing citizenship provisions relatively well, at least once the relevant directives are taken alongside the rights enumerated in the Treaties. As Schmidt notes, it has been the reading in of an aspirational, transnational, account of citizenship by the Court post Grzelczek that has distorted the justified balance between the rights of European citizenship and their duties towards (as well as of) national citizens that lies at the heart of this status. Similarly, though Ferrera tackles a genuine and pressing issue in an innovative and imaginative way, I believe his approach will have not only more appeal but also a better justification through being grounded in an inter- rather than a supra- national account of European citizenship.

Open Access This chapter is licensed under the terms of the Creative Commons Attribution 4.0 International License (http://creativecommons.org/licenses/by/4.0/), which permits use, sharing, adaptation, distribution and reproduction in any medium or format, as long as you give appropriate credit to the original author(s) and the source, provide a link to the Creative Commons license and indicate if changes were made.

The images or other third party material in this chapter are included in the chapter's Creative Commons license, unless indicated otherwise in a credit line to the material. If material is not included in the chapter's Creative Commons license and your intended use is not permitted by statutory regulation or exceeds the permitted use, you will need to obtain permission directly from the copyright holder. 